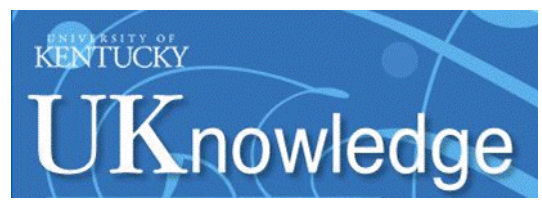

University of Kentucky

UKnowledge

4-7-2016

\title{
Photocatalytic Reduction of Fumarate to Succinate on ZnS Mineral Surfaces
}

\author{
Ruixin Zhou \\ University of Kentucky, ruixin.zhou@uky.edu \\ Marcelo I. Guzman \\ University of Kentucky, marcelo.guzman@uky.edu
}

Follow this and additional works at: https://uknowledge.uky.edu/chemistry_facpub

Part of the Analytical Chemistry Commons, Biochemistry Commons, Biogeochemistry Commons, Cosmochemistry Commons, Environmental Chemistry Commons, Environmental Sciences Commons, Organic Chemistry Commons, Physical Chemistry Commons, and the Systems Biology Commons Right click to open a feedback form in a new tab to let us know how this document benefits you.

\section{Repository Citation}

Zhou, Ruixin and Guzman, Marcelo I., "Photocatalytic Reduction of Fumarate to Succinate on ZnS Mineral Surfaces" (2016). Chemistry Faculty Publications. 67.

https://uknowledge.uky.edu/chemistry_facpub/67

This Article is brought to you for free and open access by the Chemistry at UKnowledge. It has been accepted for inclusion in Chemistry Faculty Publications by an authorized administrator of UKnowledge. For more information, please contact UKnowledge@lsv.uky.edu. 


\section{Photocatalytic Reduction of Fumarate to Succinate on ZnS Mineral Surfaces}

Digital Object Identifier (DOI)

http://dx.doi.org/10.1021/acs.jpcc.5b12380

\section{Notes/Citation Information}

Published in The Journal of Physical Chemistry C, v. 120, issue 13, p. 7349-7357.

Copyright @ 2016 American Chemical Society

ACS AuthorChoice - This is an open access article published under an ACS AuthorChoice

License, which permits copying and redistribution of the article or any adaptations for noncommercial purposes. 


\title{
Photocatalytic Reduction of Fumarate to Succinate on ZnS Mineral Surfaces
}

\author{
Ruixin Zhou and Marcelo I. Guzman* \\ Department of Chemistry, University of Kentucky, Lexington, Kentucky 40506, United States \\ Supporting Information
}

ABSTRACT: The reductive tricarboxylic acid (rTCA) cycle is an important central biosynthetic pathway that fixes $\mathrm{CO}_{2}$ into carboxylic acids. Among the five reductive steps in the rTCA cycle, the two-electron reduction of fumarate to succinate proceeds nonenzymatically on the surface of photoexcited sphalerite $(\mathrm{ZnS})$ colloids suspended in water. This model reaction is chosen to systematically study the surface photoprocess occurring on $\mathrm{ZnS}$ in the presence of $\left[\mathrm{Na}_{2} \mathrm{~S}\right](1-10 \mathrm{mM})$ hole scavenger at $15{ }^{\circ} \mathrm{C}$. Experiments at variable $\mathrm{pH}(5-10)$ indicate that monodissociated fumaric acid is the primary electron acceptor forming the monoprotic form of succinic acid. The following reaction scheme is proposed: (1) photoexcitation of $\mathrm{ZnS}$ generates conduction band electrons and valence band holes, (2) the hole scavenger donates electrons while producing sulfur-containing intermediates en route to sulfate formation, (3) a first electron transfer occurs at the conduction band converting chemisorbed monoprotic fumaric acid at surface zinc sites into an adsorb radical anion, and (4) the radical anion

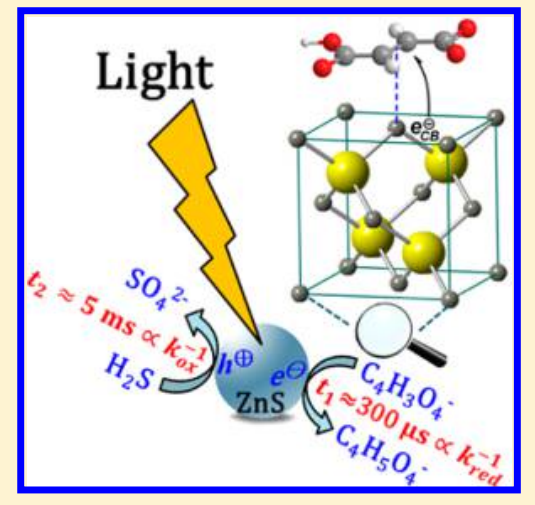
accepts a second electron and forms an adsorbed carbanion, which (5) abstracts two protons consecutively from either hydronium ion (acidic condition) or water (neutral and basic condition) to be desorbed as monodissociated succinic acid. The apparent quantum yield measurement of succinate production $\left(\Phi_{\mathrm{s}}\right)$ under periodic irradiation at $\lambda \geq 305 \mathrm{~nm}$ shows that the time scale of electron transfer on the conduction band $\left(t_{1}\right)$ and valence band hole loss $\left(t_{2}\right)$ are in the order of hundred microseconds and a few milliseconds, respectively. These transitions $\left(t_{1}\right.$ and $\left.t_{2}\right)$ become undistinguishable at $520 \mu \mathrm{s}$ for a zeta potential $\zeta=-22.09 \mathrm{mV}$ corresponding to $\left[\mathrm{Na}_{2} \mathrm{~S}\right]=0.57 \mathrm{mM}$. Overall, this work provides new insights to model heterogeneous processes such as the reduction of $\mathrm{CO}_{2}$ occurring on the surface of photocatalysts and advance present understanding of photocatalytic reactions.

\section{INTRODUCTION}

The photocatalytic harvesting of solar photons can potentially address the growing demand of energy supply faced worldwide. ${ }^{1}$ In this context, photocatalytic studies have largely focused their attention in producing renewable $\mathrm{H}_{2}(\mathrm{~g})$ from water splitting, ${ }^{2}$ while more recently the reduction of $\mathrm{CO}_{2}$ has regained attention as a possible mechanism to fix this atmospheric greenhouse gas and produce useful hydrocarbon fuels. $^{3-5}$ In general, the reported difficulty for promoting the photocatalytic reduction of $\mathrm{CO}_{2}$ is the high initial energy cost of the one-electron reduction to produce $\mathrm{CO}_{2}{ }^{\bullet-}$, which has a standard reduction potential $E^{0}=-1.85 \mathrm{~V}$ at $\mathrm{pH} 7 .^{5}$ Efforts to improve the low quantum yield of typical reductions have proposed to control the properties of photocatalysts to increase the number of photoexcited carriers on the surface where the reaction takes place. ${ }^{2}$ Surface modifications that activate the semiconductor also facilitate charge separation, ${ }^{2}$ suggesting the importance of measuring the lifetimes of surface excited states. Recently, various doping of nanostructures, combinations of semiconductors, and the addition of sensitizers were explored. ${ }^{5}$ However, a central physical chemistry concept that has been ignored $^{5}$ until our previous publication ${ }^{3}$ is that the effective transfer of electrons to adsorbed substrates occurs in relatively slow time scales. ${ }^{3}$
In addition to the energy applications discussed above, prebiotic chemists have been interested in the use of photocataysis to drive a cycle of carbon fixation inspired in the reductive tricarboxylic acid (rTCA) cycle relevant to the origin of life. ${ }^{6-10}$ The origin of life is one of the most important unsolved questions of science, ${ }^{11}$ which combines several diverse disciplines, including physical chemistry. A further discussion to context of this research in the origin of life field is presented in the Supporting Information. Photocatalyzed reactions have been proposed as fundamental for the origin of life $\mathrm{e}^{6-10,12-14}$ by directly providing carboxylic acids to the rTCA cycle. ${ }^{7-10}$ The photoexcitation of mineral semiconductors by sunlight opens new reaction pathways through the generated excited-state species and radicals. ${ }^{10}$ For example, three out of five reductions from the rTCA cycle can be driven by photocatalysis on the surface of $\mathrm{ZnS}$ colloids suspended in water using $\mathrm{Na}_{2} \mathrm{~S}$ hole scavenger. ${ }^{7,10}$ The stoichiometric yields of the conversion from oxaloacetate to malate, fumarate to succinate, and 2oxoglutarate to oxalosuccinate were 75,95 , and $2.5 \%$, respectively. ${ }^{10}$ The low yield for the reductive carboxylation

Received: December 18, 2015

Revised: March 17, 2016

Published: March 17, 2016 
of 2-oxoglutarate to oxalosuccinic acid, its consecutive reduction to form cis-aconitic acid, and the reductive carboxylation of succinic acid to 2-oxoglutaric acid have been difficult to achieve. ${ }^{10}$ Furthermore, the actual photocatalytic mechanism of the working reductive steps has remained unexplored. ${ }^{6}$

The focus of this study on $\mathrm{ZnS}$ factors in that the photocatalyst was indicated as an excellent mineral present in Hadean environments due to its stability with respect to $\mathrm{ZnCO}_{3}{ }^{10,14}$ The conduction-band electrons of the semiconductor have a sufficiently negative reduction potential $(-1.04 \mathrm{~V}$ vs NHE) to drive all the reductions steps in the rTCA cycle. $^{10,14}$ Moreover, $\mathrm{ZnS}$ can harvest energy from the sun's photons to promote the reaction under study, which is slow by thermal chemistry alone. ${ }^{10,14}$ In our previous work, the reduction of $\mathrm{CO}_{2}$ to formate $\left(\mathrm{HCOO}^{-}\right)$was reported in great detail using illuminated aqueous suspensions of $\mathrm{ZnS}$ semiconductor as the catalysts. ${ }^{3}$ The work developed new methods to study photoreductions reactions ${ }^{3}$ and pointed out that to enable any progress in this field, further understanding of the photocatalytic processes and the associated surface mechanisms are needed. In this context, the production of $\mathrm{C}-$ $\mathrm{C}$ coupling dimers in a mixture of 2,5-dihydrofuran and tetrahydrofuran on irradiated $\mathrm{ZnS}$ indicates the surface reactivity of adsorbates with double bonds. ${ }^{15}$

In this work, the efficient and specific reduction of fumarate to succinate is purposely chosen as a model reaction to study the heterogeneous mechanism on $\mathrm{ZnS}$. In this system, the reaction is not governed by the equilibrium thermodynamics, as for biological systems, because it should proceed favorably $\left(E^{\circ}\right.$ $=+0.031 \mathrm{~V}, \mathrm{pH} 7.0$ and $298 \mathrm{~K}) .{ }^{16}$ Instead, the reaction is sluggish due to kinetics limitations that can be reversed without the generation of side products upon irradiation of $\mathrm{ZnS}$ to proceed efficiently. This work aims to gain new fundamental understanding of the photocatalytic process, compare it to that of $\mathrm{CO}_{2}$ reduction, ${ }^{3}$ and provide insights conducting to improving the efficiency for the reductive carboxylation reactions on $\mathrm{ZnS}$, e.g., for 2-oxoglutarate. The determination of the bandgap of synthesized $\mathrm{ZnS}$ nanocrystallites suspended in water is explored by quantifying the rate of succinate production $R_{\mathrm{s}}$ at different cut-off wavelengths of irradiation ( $\left.\lambda_{\text {cut-off }}\right)$. After studying the effect of $\mathrm{pH}$ on $R_{\mathrm{s}}$, the apparent quantum yields of succinate production $\left(\Phi_{\mathrm{s}}\right)$ at $\lambda=325 \pm 20$ $\mathrm{nm}$ are determined under continuous and periodic irradiation. The dependence of $\Phi_{s}$ on $\left[\mathrm{Na}_{2} \mathrm{~S}\right]$ yields information to distinguish the time scales for hole loss and electron transfer for the model system. Finally, all observations are summarized in a proposed reaction mechanism showing the importance of adsorption processes as a limiting factor regulating the transfer time scale of charge carriers in photocatalysis.

\section{EXPERIMENTAL DETAILS}

Catalyst Preparation. $\mathrm{ZnS}$ photocatalyst was freshly prepared at a loading of $2.3 \mathrm{~g} \mathrm{~L}^{-1}$ by dropwise addition of $100 \mathrm{~mL}$ of $50 \mathrm{mM} \mathrm{Na} \mathrm{S}_{2}$ (99.1\% assay, Sigma-Aldrich) to 100 $\mathrm{mL}$ of $50 \mathrm{mM} \mathrm{ZnSO}{ }_{4}\left(\mathrm{ZnSO}_{4} \cdot 7 \mathrm{H}_{2} \mathrm{O}\right.$, Sigma-Aldrich ReagentPlus, 99.0\%) under continuous $\mathrm{N}_{2}(\mathrm{~g}$ ) (UHP, ScottGross) sparging. ${ }^{3}$ Degassed ultrapure water $(18.2 \mathrm{M} \Omega \mathrm{cm}$, Elga Purelab Flex, Veolia) was used in all experiments. The concentration of stocked sulfide solution was measured after a 1:100 dilution with $2.00 \mathrm{M} \mathrm{NaOH}$ (99.3\% assay, Fisher Chemicals) using a sulfide ion selective electrode (Thermo, Orion 94-16). ${ }^{3}$ The previously diluted sulfide solution was further diluted with an equal volume of $2.00 \mathrm{M} \mathrm{NaOH}$ and then titrated with $100 \mathrm{mM}$ cadmium nitrate (cadmium nitrate tetrahydrate, Aldrich, $\geq 99.0 \%$ ). ${ }^{3}$ The concentration of sulfide hole scavenger during photoirradiation was potentiometrically quantified using a calibration curve. The decrease of sulfide concentration followed a first-order decay curve with a correlation coefficients $r^{2}>0.998$.

Photoirradiation Experiments. Experiments were performed by placing $100 \mathrm{~mL}$ of $\mathrm{ZnS}$ suspension in a $200 \mathrm{~mL}$ customized cylindrical quartz photoreactor surrounded with a water jacket. ${ }^{3}$ The temperature was kept at $15{ }^{\circ} \mathrm{C}$ by flowing water through the photoreactor from a circulating bath (Thermo Scientific SC100-A25). ${ }^{3}$ A $1 \mathrm{~kW}$ high-pressure $\mathrm{Hg}(\mathrm{Xe})$ arc lamp provided with a water filter, to remove infrared radiation, was used in combination with a cut-off optical filter. Optical filters with a cut off wavelength $\lambda_{\text {cut-off }}=$ $280,295,305,320$, and $400 \mathrm{~nm}$ were used in selected experiments. ${ }^{3}$ Results report the average of duplicate experiments with one standard deviation. In a typical experiment, the reduction of fumarate to succinate in an aqueous suspension of $\mathrm{ZnS}$ was conducted under continuous irradiation at $\lambda \geq 305$ $\mathrm{nm}$. A volume of $0.25 \mathrm{~mL}$ of $\left[\mathrm{Na}_{2} \mathrm{~S}\right]=3.270 \mathrm{M}$ was added to the colloidal suspension, which was augmented with $1.0 \mathrm{mmol}$ sodium fumarate (Alfa Aesar, 99.6\% assay). The initial concentration of sulfide was $\sim 8.0 \mathrm{mM}(\mathrm{pH} \approx 12.10)$ and dropped to $\sim 2.0 \mathrm{mM}$ upon adjustment to $\mathrm{pH} \sim 7.05$ with $\mathrm{H}_{2} \mathrm{SO}_{4}$ (Acros Organics, 98.0\%).

$\Phi_{s}$ was determined under continuous and periodic illumination from the ratio of rate of succinate production to the effective photon flux. The effective photon flux for the wavelength range $325 \pm 20 \mathrm{~nm}$ was determined by potassium ferrioxalate actinometry after convoluting the spectrum of the actinometer $^{17}$ with that reported for the catalyst in water. ${ }^{3}$ Light modulation by pulses from 0.02 to $2400 \mathrm{~Hz}$, for illuminated periods lasting $\tau_{\mathrm{L}}=0.208 \mathrm{~ms}-25 \mathrm{~s}$ on, was provided by a mechanical shutter and optical choppers as described previously. ${ }^{3}$ Aliquots $(5 \mathrm{~mL})$ were extracted from the reactor every $20 \mathrm{~min}$ and centrifuged at $4400 \mathrm{rpm}$ for $5 \mathrm{~min}$ in the dark. Sulfide concentrations were monitored with the ion selective electrode as described above for experiments with initial $\left[\mathrm{Na}_{2} \mathrm{~S}\right]_{0}=1.03,2.03,5.07$, and $10.07 \mathrm{mM}$.

Control experiments (Table 1) were designed to prove that the only operative mechanism for fumarate reduction was

Table 1. Control Experiments to Demonstrate the Photocatalytic Production of Succinate

\begin{tabular}{|c|c|c|c|c|c|}
\hline & \multicolumn{4}{|c|}{ conditions } & \multirow{2}{*}{$\begin{array}{c}\text { product } \\
\text { succinate }\end{array}$} \\
\hline & $\mathrm{ZnS}$ & UV & fumarate & hole scavenger & \\
\hline experiment & + & + & + & + & + \\
\hline control A & - & + & + & + & - \\
\hline control B & + & - & + & + & - \\
\hline control C & + & + & - & + & - \\
\hline control D & + & + & + & - & - \\
\hline control E & + & + & + & $+^{a}$ & + \\
\hline
\end{tabular}

photocatalysis. Each control tested whether succinate production proceeded or not in the absence of one of the following conditions: $\mathrm{ZnS}$ (control A), light ( $h v)$ (control B), fumarate (control C), and hole scavenger (controls D). Alternatively, the use of $8.0 \mathrm{mM}$ sodium sulfite (99.9\% assay, Fisher Chemicals) instead of $\mathrm{Na}_{2} \mathrm{~S}$ as the hole scavenger was assayed in control $\mathrm{E}$. 
Analysis of Products. All samples were centrifuged at 4400 rpm for $5 \mathrm{~min}$, filtered (IC Acrodisc $0.2 \mu \mathrm{m}$ pore size; Pall Corp.) to discard the precipitate, and diluted 8 times for analysis with a Dionex ICS-2000 ion chromatography system. ${ }^{3}$ This system was equipped with an AS autosampler (Dionex), a suppressor, a hydroxide $\left(\mathrm{OH}^{-}\right)$eluent generator $(\mathrm{KOH}$ cartridge EGC III, $0.38 \mathrm{~mL} / \mathrm{min}$ as the flow rate), an anion trap column (CR-ATC), and a conductivity detector. Chromatographic separation of anions was carried out with an IonPac AS11-HC analytical column $(2 \times 250 \mathrm{~mm})$ coupled with an IonPac AG11-HC guard column $(2 \times 50 \mathrm{~mm}){ }^{3}$ The initial $1 \mathrm{mM}$ hydroxide concentration was kept constant for 8 min and then increased linearly to $15 \mathrm{mM}$ for $10 \mathrm{~min}$, followed by a second gradient to $30 \mathrm{mM}\left[\mathrm{OH}^{-}\right]$for $10 \mathrm{~min}$, and a third increment to $60 \mathrm{mM}$ for $10 \mathrm{~min}^{3} \mathrm{~A} 0.12 \mathrm{~mL} \mathrm{~min}^{-1}$ flow of 0.42 $\mathrm{mM}$ formic acid (Fisher Optima LC-MS grade, $99.6 \%$ assay) in methanol (Fisher Optima LC/MS grade, $99.99 \%$ assay) was mixed with the chromatographic eluent through a Tee connection. $^{3}$ A mass spectrometer (Thermo MSQ Plus) interfaced by an electrospray ionization probe operating in negative ion mode allowed sample identification of the mass-tocharge ratio $(\mathrm{m} / \mathrm{z})$ of anions in the mixed flow. The optimized mass spectrometry parameters were needle voltage $1.9 \mathrm{kV}$, cone voltage $50 \mathrm{~V}$, probe temperature $450{ }^{\circ} \mathrm{C}$, and nitrogen nebulizing 70 psi. $^{3}$ Anions identified by mass spectrometry included fumarate $(\mathrm{m} / z 115)$, succinate $(\mathrm{m} / z 117)$, bicarbonate $(\mathrm{m} / z 61)$, bisulfite $(\mathrm{m} / z \mathrm{81})$, bisulfate $(\mathrm{m} / z$ 97), hydrogen thiosulfate $(m / z 113)$, and hydrogen dithionite $(m / z 129)$. Succinate was quantified from calibration curves prepared with sodium succinate (Alfa Aesar, 99.75\% assay). In selected experiments, the concentration of fumarate was also monitored based on the comparison of integrated chromatographic peak areas to a calibration curve prepared using sodium fumarate.

Mineral Characterization. The characterization and stability of the mineral were assessed after drying samples of $\mathrm{ZnS}$ as described before ${ }^{3}$ by powder X-ray diffraction (XRD) and Raman spectroscopies as well as by transmission electron microscopy (TEM). In summary, XRD spectra and TEM micrographs show the catalyst is the same before, during, after irradiation, and even after a second round of photolysis experiments when reusing $\mathrm{ZnS} .^{3}$

The concentration of dissolved $\mathrm{Zn}^{2+}$ during photoirradiation experiments was measured every $30 \mathrm{~min}$ by atomic absorption spectroscopy (Thermo Scientific iCE 3000 Series) at $\lambda=213.9$ $\mathrm{nm}$ using a $\mathrm{Zn}$ hollow cathode lamp with a flame made of acetylene and air (both Scott Gross, UHP grade). A calibration curve was prepared with the same matrix using a nonirradiated sample under the same experimental conditions.

\section{RESULTS AND DISCUSSION}

Identification of Products. Figure 1 shows the ion chromatogram of species identified as products during the reduction of fumarate on $\mathrm{ZnS}$ colloids irradiated for $2 \mathrm{~h}$ at $\lambda \geq$ $305 \mathrm{~nm}$. The separated chromatographic peaks correspond to anions eluting with $m / z$ values with a retention time $\left(t_{\mathrm{r}}\right)$ : succinic acid monoanion $\left(\mathrm{m} / z=117, t_{\mathrm{r}}=18.07 \mathrm{~min}\right)$, bisulfite $\left(\mathrm{m} / z=81, t_{\mathrm{r}}=18.85 \mathrm{~min}\right)$, bicarbonate $\left(\mathrm{m} / z=61, t_{\mathrm{r}}=19.25\right.$ $\min )$, bisulfate $\left(m / z=97, t_{\mathrm{r}}=19.32 \mathrm{~min}\right)$, fumaric acid monoanion $\left(m / z=115, t_{\mathrm{r}}=20.06 \mathrm{~min}\right)$, hydrogen thiosulfate $\left(\mathrm{m} / z=113, t_{\mathrm{r}}=24.52 \mathrm{~min}\right)$, and hydrogen dithionite $(\mathrm{m} / z=$ $\left.129, t_{\mathrm{r}}=32.30 \mathrm{~min}\right)$.

The black traces in Figure 2 show examples for the production of succinate versus time at (solid squares) $\mathrm{pH}$

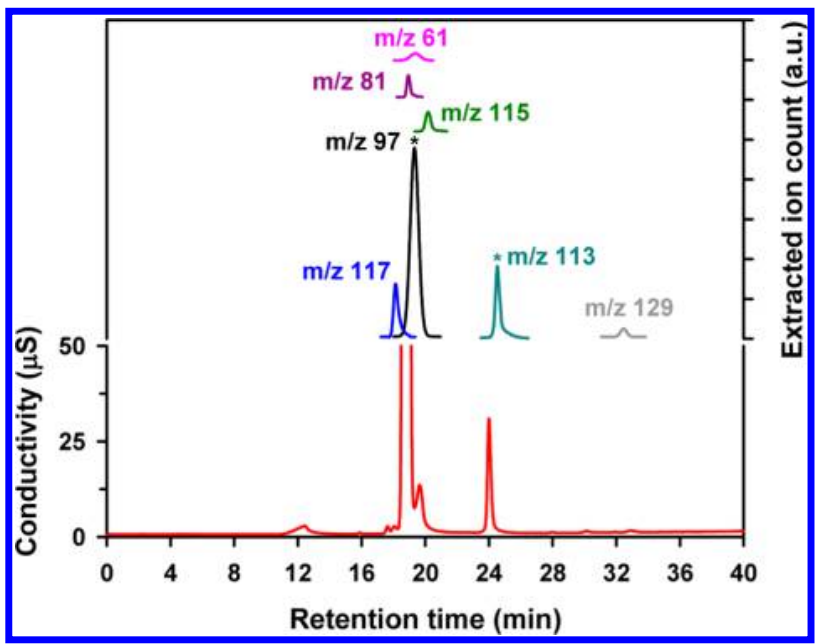

Figure 1. Ion chromatogram of a photolyzed $(\lambda \geq 305 \mathrm{~nm})$ sample of $1.0 \mathrm{mM}$ fumarate in $2.3 \mathrm{~g} \mathrm{~L}^{-1} \mathrm{ZnS}$ at $\mathrm{pH} 7.02$ for $2 \mathrm{~h}$ in the presence of $\left[\mathrm{Na}_{2} \mathrm{~S}\right]_{0}=2.0 \mathrm{mM}$. Extracted anion peaks for succinate $(\mathrm{m} / z 117)$, bicarbonate $(\mathrm{m} / z 61)$, bisulfite $(\mathrm{m} / z 81)$, bisulfate $(\mathrm{m} / z 97)$, fumarate $(m / z 115)$, hydrogen thiosulfate $(m / z 113)$, and hydrogen dithionite $(m / z 129)$ are displayed. Peaks $(*)$ at $m / z 97$ and 113 are scaled down 10 times.

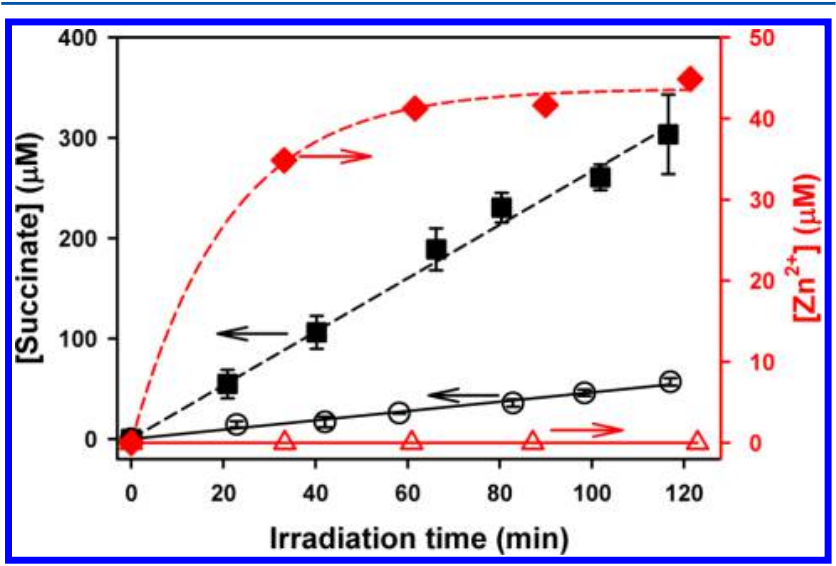

Figure 2. [Succinte] and dissolved $\left[\mathrm{Zn}^{2+}\right]$ during $2 \mathrm{~h}$ irradiation $\left(\lambda_{\text {cut-off }} \geq 305 \mathrm{~nm}\right)$. Key: empty black circle $=[$ succinate $]$ at $\mathrm{pH} 7.02$; solid black square $=[$ succinate $] \mathrm{pH} 5.32$; empty red triangle $=\left[\mathrm{Zn}^{2+}\right]$ at $\mathrm{pH}$ 7.02; solid red diamond $=\left[\mathrm{Zn}^{2+}\right]$ at $\mathrm{pH}$ 5.32. Other conditions as listed in Figure 1.

5.32 and (empty circles) 7.02. The linear fitting to the experimental data yields succinate production rates with time, $t$ $(\mathrm{min})$, of $R_{\mathrm{s}}=2.669 \mu \mathrm{M} \mathrm{min}{ }^{-1} \times t\left(r^{2}=0.992\right)$ at $\mathrm{pH} 5.32$ and $R_{\mathrm{s}}=0.464 \mu \mathrm{M} \mathrm{min} \mathrm{m}^{-1} \times t\left(r^{2}=0.984\right)$ at $\mathrm{pH}$ 7.02. Control experiments (Table 1) demonstrate that the reduction of fumarate to succinate proceeds by heterogeneous photocatalysis. Controls $\mathrm{A}-\mathrm{D}$ showed no production of succinate. Specifically, the participation of any thermal reaction contributing to the reduction of fumarate in our system is discarded by control $\mathrm{B}$ in the absence of irradiation. Interestingly, succinate production was observed when substituting $\mathrm{Na}_{2} \mathrm{~S}$ by $8.0 \mathrm{mM}$ sodium sulfite as the hole scavenger (control E). These results confirms that the reduction of fumarate proceeds with high yield and that no alternative products are generated, ${ }^{10}$ even when employing several cut-off irradiation filters $\left(\lambda_{\text {cut-off }} \geq 280,295,305\right.$, and $320 \mathrm{~nm})$ or varying the $\mathrm{pH}(5-10)$. 
The integrity of $\mathrm{ZnS}$ at low $\mathrm{pH}$ is affected as the material starts to dissolve into $\mathrm{Zn}^{2+}$ and $\mathrm{S}^{2-}$ ions (Figure 2). For example, at $\mathrm{pH} 5.32,\left[\mathrm{Zn}^{2+}\right]$ rises exponentially with time according to $\left[\mathrm{Zn}^{2+}\right]=43.7 \times\left(1-\mathrm{e}^{-0.0473 t}\right)\left(r^{2}=0.997\right)$, reaching a plateau after $1 \mathrm{~h}$ with maximum $\left[\mathrm{Zn}^{2+}\right]_{\max }=43.7 \mu \mathrm{M}$ (Figure 2). Even for this low $\mathrm{pH}$, the generated excess of $\mathrm{Zn}^{2+}$ and the adsorption of $\mathrm{H}_{3} \mathrm{O}^{+}$on the surface of $\mathrm{ZnS}$ are not sufficient to overturn the negative zeta potential $\zeta_{\mathrm{pH}=5}=-20.12$ $\mathrm{mV}^{3,18}$ This $\mathrm{pH}$-dependent dissolution of $\mathrm{ZnS}$ should not be confused with corrosion, which was observed in the absence of hole scavenger (e.g., $\left[\mathrm{Zn}^{2+}\right]=365.59 \mu \mathrm{M}$ at $\mathrm{pH}=7.02$ after irradiation for $2 \mathrm{~h}$ ). The photodecomposition of $\mathrm{ZnS}$ can proceed via an irreversible reduction of lattice zinc ions by conduction band electrons and the oxidation of lattice sulfide ions by holes. ${ }^{19}$ Therefore, the presence of dissolved sulfide ion hole scavenger in the experiment allows the reversal of photooxidation by providing a substitution mechanism that contributes to maintain the stability of $\mathrm{ZnS}$ during illumination. ${ }^{19}$ At $\mathrm{pH} \geq 7.0$, no dissolved $\mathrm{Zn}^{2+}$ was observed during irradiation, as depicted in the experiment at $\mathrm{pH} 7.02\left(\zeta_{\mathrm{pH}=7}=\right.$ $-31.09 \mathrm{mV}$ ) in Figure 2, proving the stability of the catalyst.

The production of elemental (rhombic) sulfur $\left(\mathrm{S}_{8}\right)$ during photoirradiation was observed as a slight yellow color developed over the white background colloidal suspension. Raman microspectroscopy provided a confirmation for the generation of $\mathrm{S}_{8}{ }^{3}$ A photoxidation mechanism in the presence of $\mathrm{HS}^{-}$hole scavenger prevents the photodegradation of the photocatalyst by substituting $S^{2-}$ to the photooxidized lattice sites. ${ }^{19}$ As a result, $S_{8}$ is produced during irradiation from the oxidation of sulfide hole scavenger.

Identification of a Monoanion Intermediate as the Primary Electron Acceptor. Fumaric acid $\left(\mathrm{pK}_{\mathrm{a} 1}=3.02\right.$ and $\mathrm{p} K_{\mathrm{a} 2}=4.38$ at $\left.25^{\circ} \mathrm{C}\right)^{20}$ can dissociate twice as indicated by the sequence of equilibrium reactions 1 and 2 :

$$
\begin{aligned}
& \mathrm{HOOC}-\mathrm{CH}=\mathrm{CH}-\mathrm{COOH} \\
& \quad \rightleftarrows \mathrm{HOOC}-\mathrm{CH}=\mathrm{CH}-\mathrm{COO}^{-}+\mathrm{H}^{+} \\
& \mathrm{HOOC}-\mathrm{CH}=\mathrm{CH}-\mathrm{COO}^{-} \\
& \quad \rightleftarrows{ }^{-} \mathrm{OOC}-\mathrm{CH}=\mathrm{CH}-\mathrm{COO}^{-}+\mathrm{H}^{+}
\end{aligned}
$$

Based on the speciation of fumaric acid for $\mathrm{pH}<\mathrm{p} K_{\mathrm{a} 1}$, the diprotic form $\left(\mathrm{H}_{2} \mathrm{~A}\right)$ is the major species present in equilibrium, and the completely dissociated form $\left(\mathrm{A}^{2-}\right)$ is the dominant species for $\mathrm{pH}>\mathrm{pK} K_{\mathrm{a} 2}$. For the intermediate $\mathrm{pH}$ range bracketed between $\mathrm{p} K_{\mathrm{a} 1}$ and $\mathrm{p} K_{\mathrm{a} 2}$, the monoanion form $\left(\mathrm{HA}^{-}\right)$of fumaric acid becomes the main species in equilibrium. The same concept applies to describe the dissociation of succinic acid, as a diprotic acid $\left(\mathrm{p} K_{\mathrm{a} 1}=4.21 \text { and } \mathrm{p} K_{\mathrm{a} 2}=5.64\right)^{20}$ product. Figure 3 shows the dependence of the rate of succinate production $R_{\mathrm{s}}$ on $\mathrm{pH}$ and the speciation curves for the diprotic species succinic acid in the $\mathrm{pH}$ range 5.06-10.09. The direct correlation of the experimental $R_{\mathrm{s}}$ data to the calculated fraction of succinic acid monoanion $\left(\mathrm{HA}^{-}\right)$suggests this preferred photoproduct is directly generated from adsorbed monoprotic furmaric acid. In consequence, adsorbed fumaric acid monoanion is reduced by the sequential transfer of two electrons. These results agree with the trend observed for a smaller number of experiments that also monitored the initial rate of fumaric acid loss at variable $\mathrm{pH}$.

The resembling behavior of both $R_{\mathrm{s}}$ and the fraction of succinic acid monoanion with $\mathrm{pH}$ depicts the surface reaction of adsorbed fumaric acid monoanion to start through a weak $\pi$ -

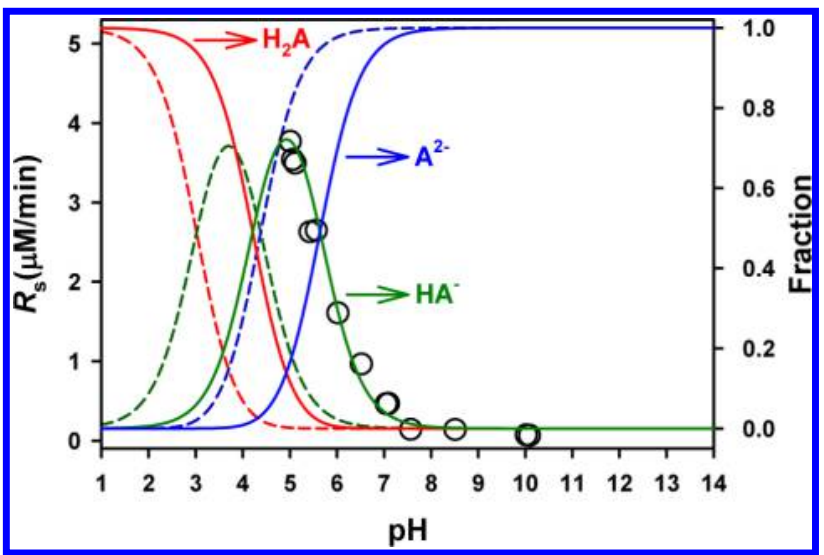

Figure 3. Rate of succinate production $\left(R_{\mathrm{s}}\right)$ for $\lambda \geq 305 \mathrm{~nm}$ at variable $\mathrm{pH}$ and corresponding fractions of (dashed line) fumaric and (solid line) succinic acids available as diprotic acid $\left(\mathrm{H}_{2} \mathrm{~A}\right.$, red trace), monoanion $\left(\mathrm{HA}^{-}\right.$, green trace), and dianion $\left(\mathrm{A}^{2-}\right.$, blue trace) species. Other conditions as listed in Figure 1.

bond interaction with an active zinc site. The undissociated $-\mathrm{COOH}$ group of fumaric acid monoanion is in closer proximity to the surface than the dissociated $-\mathrm{COO}^{-}$group. A lone pair of electrons in the $\mathrm{C}=\mathrm{O}$ moiety of the $-\mathrm{COOH}$ group could facilitate this configuration by establishing a second weak interaction with a contiguous zinc site. Instead, the dissociated $-\mathrm{COO}^{-}$group of fumaric acid monoanion is initially repelled from the negatively charged surface of $\mathrm{ZnS}$ with a point of zero charge at $\mathrm{pH} 4.2$. $^{3}$ The adsorption of the monoanion of fumaric acid by $\mathrm{ZnS}$ must occur reversibly ${ }^{21}$ in an adsorption-desorption equilibrium that is quickly established. The fast equilibrium proposed is needed to justify the quantification of dissolved species in the bulk liquid. However, the interchange between adsorbed and dissolves species must be slow as compared to the generation of excited states during illumination.

As stated above, the $\mathrm{pH}$ regulates the strength of the electrostatic interactions between fumaric and succinic acids with the nanoparticles of $\mathrm{ZnS}$. While the associated binding constants for the process considered remains unknown, they can be assumed to be quite small so that the interaction between both substrates and the particles are labile. ${ }^{22}$ For low $\mathrm{pH}$, the zeta-potential of $\mathrm{ZnS}$ becomes considerably less negative $\left(\zeta_{\mathrm{pH}=5}=-20 \mathrm{mV}\right)^{3}$ than at neutral conditions, while simultaneously the fraction of monodissociated carboxylic acid decreases as the concentration of the diprotic species growths. This intermediate protic form may also represent the optimized structure for succinic acid to be desorbed from the surface preventing the reverse charge transfer reaction between succinic acid and a hole. Therefore, the $\mathrm{pH}$ of the colloidal suspension plays a role for the optimum adsorption to balance out the surface charge of the nanoparticles and the availability of less repulsive substrates. Overall, the photocatalytic reduction of fumaric acid on the surface of $\mathrm{ZnS}$ proceeds through the most stable configuration of the intermediate formed on the surface. During the progression of the reaction, this intermediate is depleted and replenished on the surface by other molecules of fumaric acid available.

Bandgap Determination of $\mathrm{ZnS}$ in Water from Reaction Rates. The bandgap energy of $\mathrm{ZnS}$ colloidal suspensions in water was reported in our previous study based on the dependence of the reaction rate of formic acid 
production from $\mathrm{CO}_{2}\left(R_{\mathrm{HCOO}^{-}}\right)$on the cut-off wavelength of irradiation. $^{3}$ This work serves as a new demonstration that measuring a reaction rate such as the reduction of fumarate to succinate on photoexcited $\mathrm{ZnS}$ reveals the bandgap energy of the semiconductor suspended in water. The measured rate of succinate production in units of $\mu \mathrm{M} \mathrm{min} \min ^{-1}$ is $R_{\mathrm{s}}=0.739 \pm$ $0.020\left(r^{2}=0.994\right), 0.600 \pm 0.022\left(r^{2}=0.986\right), 0.464 \pm 0.002$ $\left(r^{2}=0.984\right)$, and $0.298 \pm 0.002\left(r^{2}=0.992\right)$, for irradiation at $\lambda_{\text {cut-off }} \geq 280,295,305$, and $320 \mathrm{~nm}$, respectively. No production of succinate was observed for irradiation at $\lambda_{\text {cut-off }}$ $\geq 400 \mathrm{~nm}$. Figure 4 shows the linear regression fitting of the

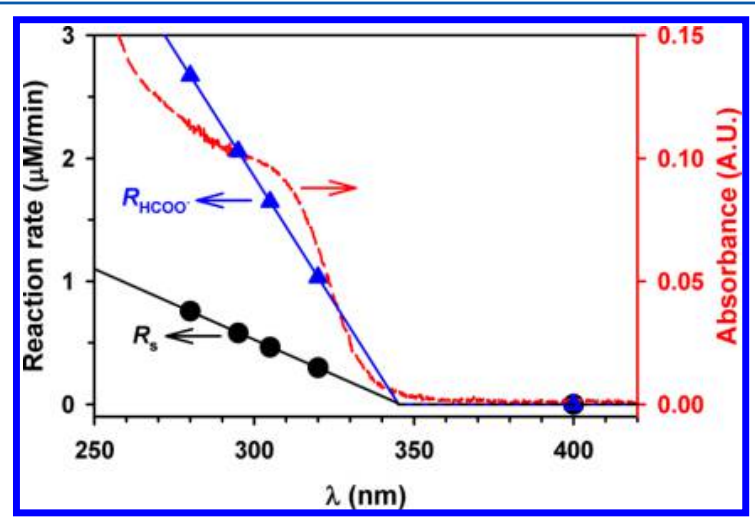

Figure 4. Reaction rate of (black circle) succinate $\left(R_{s}\right)$ production vs cut-off wavelengths of irradiation. Other conditions as listed in Figure 1. For comparison, the reaction rate of (blue triangle) formate production $\left(R_{\mathrm{HCOO}^{-}}\right)$from $\mathrm{CO}_{2}$ and the diffused reflectance absorption spectrum of $\mathrm{ZnS}$ in water from ref 3 are included.

four quantifiable fumarate production rates vs $\lambda_{\text {cut-off }}$ in which

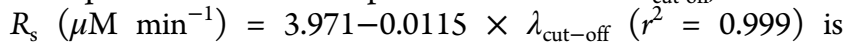
extrapolated to $R_{\mathrm{s}}=0$ to intercept the abscise at $\lambda_{\text {cut-off }}=345$ $\mathrm{nm}$. This extrapolated value represents the minimum energy required to excite the mineral catalyst for the photoreduction of fumarate to occur, which corresponds to $E_{\mathrm{BG}}$ for $\mathrm{ZnS}$.

The extrapolated value of $\lambda_{\text {cut-off }}=345 \mathrm{~nm}$ is in an excellent agreement with the measured photoreduction rate of $\mathrm{CO}_{2}$ to formate on $\mathrm{ZnS} R_{\mathrm{HCOO}^{-}}(\mu \mathrm{M} / \mathrm{min})=14.152-0.0410 \times \lambda_{\text {cut-off }}$ $\left(r^{2}=0.995\right){ }^{3}$ Thus, this wavelength can be used to obtain the bandgap of the semiconductor accordingly to $E_{\mathrm{BG}}=h c / \lambda_{\text {cut-off }}=$ $5.74 \times 10^{-19} \mathrm{~J} \equiv 3.59 \mathrm{eV}$, where $h$ is the Planck constant and $c$ is the speed of light. Therefore, this bandgap value measured during reactions in water confirms our previous finding and agrees well with the reported absorption spectrum for a colloidal suspension of $\mathrm{ZnS}$ (Figure 4). ${ }^{3}$

Apparent Quantum Yields under Continuous and Periodic Illumination. The photoreduction of fumarate on $\mathrm{ZnS}$ was studied under continuous and periodic illumination experiments at $\lambda=325 \pm 20 \mathrm{~nm}$. The effective photon flux $\left(I_{0}\right)$ was obtained after correcting the actinometric measurement by convoluting the spectrum of ferrioxalate ${ }^{17}$ with that for $\mathrm{ZnS}$ in water. $^{3}$ The calculation of the apparent quantum yield of succinate production at $\lambda=325 \pm 20 \mathrm{~nm}$ was directly derived from the ratio of the reaction rate to the effective photon flux: $\Phi_{\mathrm{s}}(\%)=100 \times R_{\mathrm{s}} / I_{0}$. This $\Phi_{\mathrm{s}}$ value represents a lower limit for the actual quantum yield because light is extinguished by absorbing and scattering particles. ${ }^{23}$ For example, experiments under continuous illumination of $2.3 \mathrm{~g} \mathrm{~L}^{-1} \mathrm{ZnS}$ with $1.0 \mathrm{mM}$ fumarate, $\left[\mathrm{Na}_{2} \mathrm{~S}\right]_{0}=2.0 \mathrm{mM}$, at $15{ }^{\circ} \mathrm{C}$ and $\mathrm{pH} 6.73$, proceed with a reaction rate $R_{\mathrm{s}}=7.74 \times 10^{-9} \mathrm{~mol} \mathrm{~L}^{-1} \mathrm{~s}^{-1}$, which combined to the measured $I_{0}=2.02 \times 10^{-7}$ einstein $\mathrm{L}^{-1} \mathrm{~s}^{-1}$ yields $\Phi_{s}=3.85 \%$.

Despite any factors that could affect the measured $\Phi_{\mathrm{s}}$ values, ${ }^{24}$ the information below if of general interest because it resolves the lifetime of redox carrier on the surface of photoexcited $\mathrm{ZnS}$ during the reduction of fumarate. For this purpose, a series of experiments applied monochromatic periodic illumination with equally lasting dark $\left(\tau_{\mathrm{D}}\right)$ and bright $\left(\tau_{\mathrm{L}}\right)$ cycles to study how $\Phi_{\mathrm{s}}$ varies in the range $208 \mu \mathrm{s} \leq \tau_{\mathrm{L}} \leq 1$ s. For example, Figure 5 shows the dependence of $\Phi_{\mathrm{s}}$ on $\tau_{\mathrm{L}}$, for

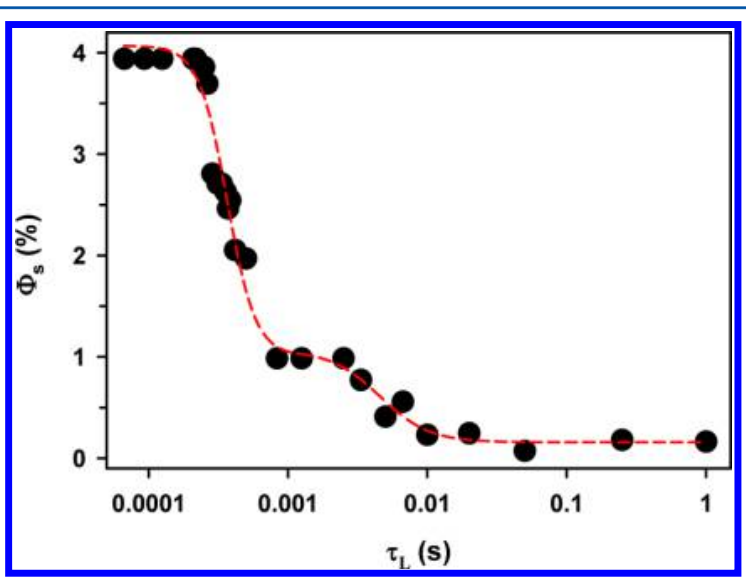

Figure 5. Apparent quantum yield of succinate production $\left(\Phi_{s}\right)$ vs the bright interval time under periodic illumination $\left(\tau_{\mathrm{L}}\right)$ of $2.3 \mathrm{~g} \mathrm{~L}^{-1} \mathrm{ZnS}$ with $1.0 \mathrm{mM}$ fumarate at $\mathrm{pH}=7.0$ and $\left[\mathrm{Na}_{2} \mathrm{~S}\right]_{0}=2.03 \mathrm{mM}$.

an initital hole scavenger concentration $\left[\mathrm{Na}_{2} \mathrm{~S}\right]_{0}=2.00$ and $\mathrm{pH}$ $=7.00$. For the fastest time intervals explored, as $\tau_{\mathrm{L}} \rightarrow 0$ the apparent quantum yield under periodic illumination $\Phi_{\mathrm{L} \rightarrow 0}$ is practically identical to that measured under the continuous irradiation $\left(\Phi_{\mathrm{s}}=3.85 \%\right)$. When moving from the measured $\Phi_{\mathrm{L} \rightarrow 0}$ value to the right in Figure 5, for progressively longer bright intervals, lower quantum yields are registered down to a minimum $\Phi_{\mathrm{L} \rightarrow \infty}=0.16 \%$ as $\tau_{\mathrm{L}} \rightarrow \infty$. During this transition from $\Phi_{\mathrm{L} \rightarrow 0}$ to $\Phi_{\mathrm{L} \rightarrow \infty}$ in Figure 5, there are two inflection points associated with redox carriers with different reactivity. ${ }^{3,25}$ After fitting a double sigmoid curve to the data in Figure 5 using nonlinear least-squares regression, the inflection points are extracted from the second derivative are $t_{1}=320 \mu \mathrm{s}$ and $t_{2}=$ $4.87 \mathrm{~ms}$.

Similar values of $t_{1}=296 \mu \mathrm{s}$ (in the order of hundreds of microseconds) and $t_{2}=4.48 \mathrm{~ms}$ (in the order of a few milliseconds) can also be obtained from the two inflection points measured when plotting the first-order rate constant of sulfide decay $\left(k_{-\mathrm{H}_{2} \mathrm{~S}}\right)$ vs $\tau_{\mathrm{L}}$, as described previously. ${ }^{3}$ While sulfide was confirmed to remain stable in dark controls, experiments under periodic illumination at variable $\left[\mathrm{Na}_{2} \mathrm{~S}\right]_{0}$ allowed the assignment of $t_{1}$ to the transfer of reducing conduction band electrons to the monoanion of fumaric acid. Accordingly, $t_{2}$ corresponds to the loss of oxidizing valenceband holes during the photooxidation of hole scavenger species. The relationship of $t_{1}$ and $t_{2}$ to the redox carriers is explained by their dependence on $\left[\mathrm{Na}_{2} \mathrm{~S}\right]_{0}=1.03,2.03,5.07$, and $10.07 \mathrm{mM}$, all values involving initial concentrations of the hole scavenger $<65 \mathrm{mM}^{3}$ of submonolayer coverage of $\mathrm{ZnS}$. The correlation of $\left[\mathrm{Na}_{2} \mathrm{~S}\right]$ versus $\zeta$ follows an exponential function reported in our previous work. $^{3}$

Considering that the surface potential of $\mathrm{ZnS}$ can be represented by $\zeta$ for unchanged permittivity and viscosity in 
the electrical double layer, ${ }^{26,27}$ an increment of $\left[\mathrm{Na}_{2} \mathrm{~S}\right]_{0}$ is associated with a more negative surface potential. Assuming that suspended $\mathrm{ZnS}$ particles under irradiation behave as microelectrodes, the surface potential of the mineral can be related to the half-reduction and half-oxidation rate constants from the Bulter-Volmer (BV) equation, ${ }^{3,25}$ which are $k_{\text {red }}=k_{0}$ $\mathrm{e}^{-\left[\alpha_{\mathrm{red}} n_{\mathrm{red}} F / R T\right]\left(E-E^{0}\right)}$ and $k_{\text {ox }}=k_{0} \mathrm{e}^{\left[\alpha_{o x} n_{\mathrm{ox}} E / R T\right]\left(E-E^{0}\right)}$, where $n_{\text {red }}$ and $n_{\text {ox }}$ are the number of electrons transferred in each half-reaction, $k_{0}$ is the standard heterogeneous rate constant, $\alpha_{\text {red }}$ and $\alpha_{\text {ox }}$ are the dimensionless charge transfer coefficients, $E$ is the excess redox potential, $E^{0}$ is the standard redox potential of $\mathrm{ZnS}, R$ is the gas constant, $F$ is the Faraday constant, and $T$ is the absolute temperature.

Figure $6 \mathrm{~A}$ shows the opposite trends that the lifetime for both redox transitions $t_{1}$ and $t_{2}$ have for increasing $\left[\mathrm{Na}_{2} \mathrm{~S}\right]_{0}$.

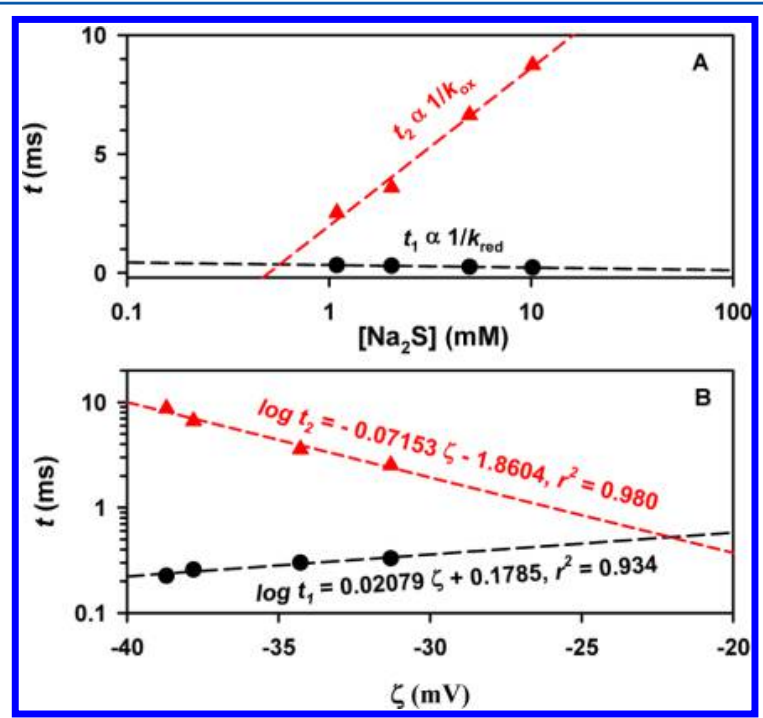

Figure 6. Transitions $(\bullet) t_{1}$ and $(\boldsymbol{\Delta}) t_{2}$ vs $(\mathrm{A})$ variable $\left[\mathrm{Na}_{2} \mathrm{~S}\right]_{0}$ and (B) zeta potential $(\zeta)$. The red solid and black dashed lines show the linear least-squares regressions, which intercept for a coverage of $\left[\mathrm{Na}_{2} \mathrm{~S}\right]=0.57 \mathrm{mM}$, corresponding to $\zeta=-22.09 \mathrm{mV}$ and $t=520 \mu \mathrm{s}$.

Figure $6 \mathrm{~B}$ displays, as predicted by the expressions for the rate constants $k_{\text {red }}$ and $k_{\text {ox }}$, the opposing trends for the dependence of $t_{1}$ and $t_{2}$ on $\zeta$. Given the opposite signs in the exponential terms of the rate constants expressions (negative for $k_{\text {red }}$ and positive for $k_{\mathrm{ox}}$ ), and the reciprocal dependence between lifetimes on rate constants, it follows that the first transition $t_{1}$ $\propto k_{\text {red }}^{-1}$ and the second transition $t_{2} \propto k_{\mathrm{ox}}^{-1}$. Therefore, as the potential represented by $\zeta$ becomes more negative (for higher $\left.\left[\mathrm{Na}_{2} \mathrm{~S}\right]_{0}\right), t_{1}$ decreases while $t_{2}$ increases in Figure 6. This interpretation agrees with $t_{1}$ being related to $k_{\text {red }}$ as reported for the reduction of $\mathrm{CO}_{2}$ on $\mathrm{ZnS}^{3}$ and the generation of gaseous $\mathrm{H}_{2}$ on $\mathrm{CdS}^{28}$ In other words, $t_{1}$ represents the overall time needed to transfer conduction band electrons to reduce fumarate to succinate. These $t_{1}$ values (from 225 to $330 \mu \mathrm{s}$ ) are well in the order of the lifetime of conduction band electrons $(\sim 200 \mu \mathrm{S})$ observed for CdSe/CdS sensitized solar cells coated with two layers of $\mathrm{ZnS}$ for a photovoltage of 0.5 $\mathrm{V}^{29}$ Similarly, $t_{2}$ characterizes the slower loss of oxidizing valence-band holes. Figure $6 \mathrm{~B}$ also includes the linear fittings to the semilog plot: $\log t_{1}=0.02079 \zeta+0.1785\left(r^{2}=0.934\right)$, and $\log t_{2}=-0.06809 \zeta+1.714\left(r^{2}=0.981\right)$. These transitions $\left(t_{1}\right.$ and $t_{2}$ ) become undistinguishable at $520 \mu$ s for a zeta potential $\zeta=-22.09 \mathrm{mV}$ corresponding to $\left[\mathrm{Na}_{2} \mathrm{~S}\right]=0.57 \mathrm{mM}$.
The relatively long times linked to electron transfer and hole loss at the surface of the photoexited $\mathrm{ZnS}^{*}$ semiconductor nanoparticles provides fundamental information to understand the dynamic process of photocatalysis. ${ }^{30}$ The measured transfer of surface carriers are relatively long $(>200 \mu$ s for the transfer of mobile electrons and a few milliseconds for loss of fixed holes) when compared with the time scales explored by time-resolved spectroscopy of semiconductors (e.g., $\left.150 \mathrm{fs} \leqslant \tau_{1 / 2}<100 \mu \mathrm{s}\right){ }^{30}$ Averages values of $\bar{t}_{1}=307 \pm 17 \mu \mathrm{s}$ and $\bar{t}_{2}=4.68 \pm 0.28 \mathrm{~ms}$ are obtained for $\left[\mathrm{Na}_{2} \mathrm{~S}\right]_{0}=2.0 \mathrm{mM}$ at $\mathrm{pH} 7$ from the data in Figures 5 and by measuring $k_{-\mathrm{H}_{2} \mathrm{~S}}$ vs $\tau_{\mathrm{L}}$. The fact that $\bar{t}_{1}$ and $\bar{t}_{2}$ are 11 and 29 times shorter than the corresponding values for the reduction of $\mathrm{CO}_{2}$ (using pure inorganic reagents) to formate under the same conditions ${ }^{3}$ indicates the structure of the adsorbate modifies the lifetime of the surface-active center of $\mathrm{ZnS}^{*}{ }^{31}$ Overall, these results reveal concepts that can be used to optimize applications of photocatalysis such as wastewater treatment, abatement of air pollution, and energy production. $^{30}$

Proposed Mechanism for the Reduction of Fumarate on ZnS. A strictly heterogeneous photoprocess is considered to propose in Scheme 1 a reaction mechanism describing the

Scheme 1. Proposed Mechanism for the Reduction of Fumarate to Succinate on Irradiated $\mathrm{ZnS}$ for the Interval $5.06 \leq \mathrm{pH}<7.00$

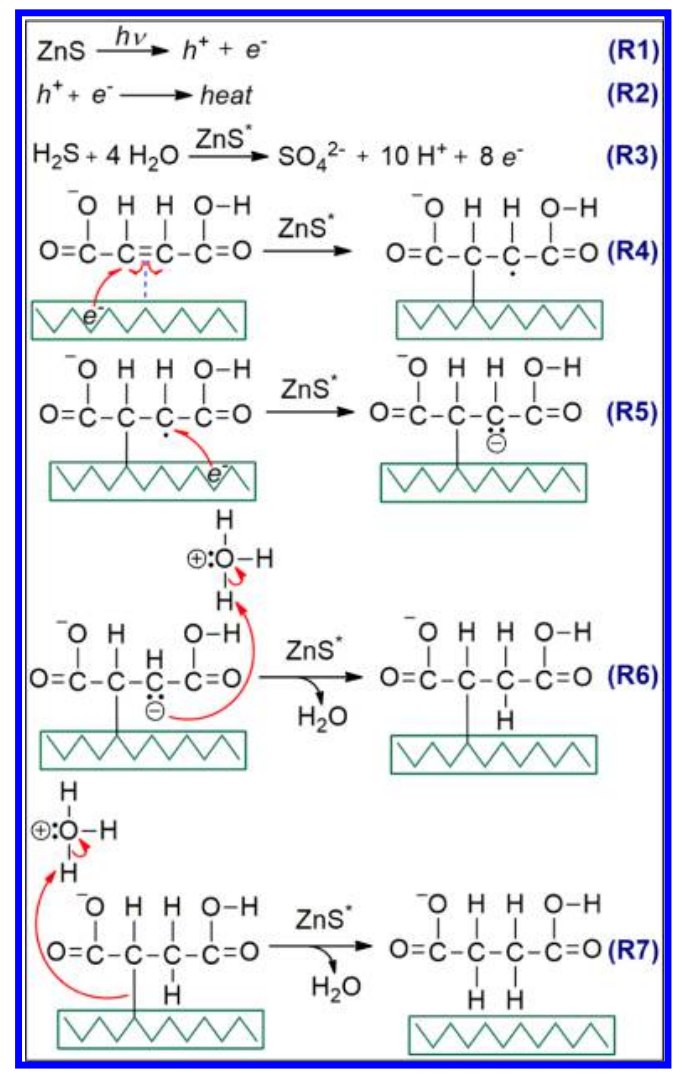

kinetic behavior observed in experiments performed under variable $\mathrm{pH}, \lambda_{\text {cut-off }} \tau_{\mathrm{L}}$ and $\zeta$. The previous assumption is useful to simplify the mechanistic scheme proposed, which is not necessarily the concluding pathway for the reactions. ${ }^{31}$ Reaction R1 in Scheme 1 shows that upon absorption of a photon $(\lambda \leq 345 \mathrm{~nm})$ by $\mathrm{ZnS}$ an oxidizing hole is created in the valence band from where an electron is promoted to the 
conduction band. ${ }^{32}$ The electron-hole pair can undergo recombination and release heat by reaction $\mathrm{R} 2$ (Scheme 1) in processes that likely involves the trapping of charge carriers by defects and the carrier recombination that occurs through such defects (recombination centers). ${ }^{31}$ The sacrificial sulfide electron donor is oxidized by valence band holes through several intermediates $\left(\mathrm{S}_{8}, \mathrm{~S}_{2} \mathrm{O}_{3}{ }^{2-}, \mathrm{SO}_{3}{ }^{2-}\right.$, and $\left.\mathrm{S}_{2} \mathrm{O}_{6}{ }^{2-}\right)$ en route to form sulfate by reaction $\mathrm{R} 3$ (Scheme 1 ). ${ }^{3}$ Simultaneously, fumaric acid is chemisorbed in dynamic equilibrium at an active zinc surface center and accepts a first electron via reaction R4 (Scheme 1). ${ }^{15}$

While the surface of $\mathrm{ZnS}$ can be considered as reversibly hydrated in an exchange that also allows adsorption of the organic molecules, this solvation process can affect the size as well as chemical and physical properties of $\mathrm{ZnS}$. For example, if $\mathrm{ZnS}$ in aqueous suspensions adsorbs a proton or hydroxide ions, either positive or negative surface charges are generated. ${ }^{33}$ The hydration mechanism of aqueous $\mathrm{ZnS}$ in water can be explained at variable $\mathrm{pH}$ as follows: ${ }^{34}$ (1) For $\mathrm{pH}<4.2$, the isoelectric point of $\mathrm{ZnS}$, the surface becomes positively charged due to the neutralization of any negative charges from sulfide sites and that dissolution releases $\mathrm{Zn}^{2+}$ (Figure 2). (2) For the interval $4.2<\mathrm{pH}<7.0$, the acquisition of negative charge by the surface is proposed to be related to the Lewis acidity of zinc sites that forms $\equiv \mathrm{SZnOH}^{-}$and release protons to the medium. (3) For basic conditions $(\mathrm{pH}>7.0)$, negative surface sites such as $\equiv \mathrm{ZnOH}^{-}$exist together with aqueous sulfide ions $\left(\mathrm{HS}^{-}, \mathrm{S}^{2-}\right)$ in the bulk solution, all contributing to the observed negative zeta-potential of $\mathrm{ZnS}$. ${ }^{35}$ However, because $\mathrm{Zn}^{2+}$ is a borderline Lewis acid, $^{36}$ the exchange of adsorbed water or hydroxide ion by surface zinc occurs so fast that these active sites are continuously available for adsorption of fumaric acid.

Two additional problems that need to be approached are: (1) What is the most stable conformational isomer adsorbed to zinc sites? (2) How does adsorption occur? Based on the acidbase equilibria that optimizes the recognition of fumaric acid by the surface-active sites of $\mathrm{ZnS}^{*}$, the mechanism in Scheme 1 depicts the monoanion species as the primary electron acceptor adsorbed on the surface to the left side of reaction R4. Considering conformational isomerism is useful to identify the most stable monoanion species adsorbed on the mineral surface to undergo photoreduction to form succinic acid monoanion. The structures of two conformational isomers for the monoanion of fumaric acid are displayed in Scheme 2, where

Scheme 2. Structure of Two Conformational Isomers of Monodissociated Fumaric Acid

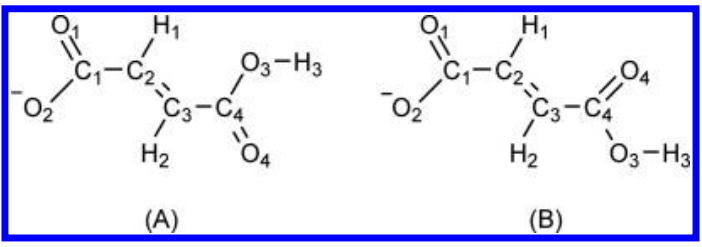

the carboxylate group is delocalized by resonance. These isomers differ mainly in the distance between the centers $\mathrm{C}_{2}$ and $\mathrm{O}_{4}$, which are calculated to be $3.56 \pm 0.04 \AA$ for isomer $\mathrm{A}$ and $2.75 \pm 0.06 \AA$ for isomer $\mathbf{B} .^{37,38}$ The higher stability of isomer $\mathbf{A}$ is supported by a computational optimization of the molecular geometry and zero-point energy of both isomers using Gaussian 09 with B3LYP density functional theory methods $^{39,40}$ and a Gaussian 6-311G (d, p) basis set ${ }^{41,42}$ we performed. Isomer $\mathbf{B}$ is predicted as less stable than isomer $\mathbf{A}$ due to steric hindrance existing between the two $\pi$ bonds.

The surface of synthesized $\mathrm{ZnS}$ exhibits a face-centered cubic structure with four tetrahedral holes in each unit cell of length $5.39 \pm 0.01 \AA^{3}{ }^{3}$ The calculated distance between two zinc centers on the surface is $3.81 \pm 0.01 \AA$ (see powder XRD measurements in ref 3 ). With all the previous considerations, Figure $7 \mathrm{~A}$ depicts the reversible adsorption of fumaric acid
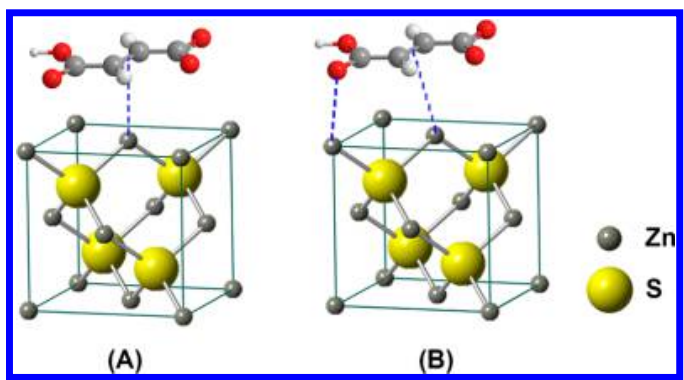

Figure 7. Adsorption of monodissociated fumaric acid on the surface of $\mathrm{ZnS}$ by interactions of (A) one zinc site to a $\pi$ bond, and (B) two zinc sites to the $\pi$ bond and a lone pair in a carbonylic oxygen atom.

monoanion that likely results from a weak olefin $\pi$ bond interaction with an active zinc site (reactant of reaction R4, Scheme 1). Similarly, the weak adsorption at a single zinc atom was observed for cyclic olefins on $\mathrm{ZnS}$, which occurs through the formation of a $\pi$-complex with an electron-deficient surface center. ${ }^{15}$ However, because the distance between two zinc sites $(3.81 \pm 0.01 \AA)$ is only slightly larger than the distance between $\mathrm{C}_{2}$ and $\mathrm{O}_{4}$ atoms for conformer $\mathbf{A}$ in Scheme $2(3.56 \pm 0.04 \AA)$, a double interaction with two zinc sites could arise from the $\pi$ bond and a lone pair from the $\mathrm{O}_{4}$ atom in conformer $\mathrm{A}$ (Figure 7B). Therefore, the second adsorption model involving a stable $\sigma$ bond appears less favorable because desorption of the product could be prevented.

Following the transfer of a first conduction band electron to the monoanion of fumaric acid, a short-lived radical centered on carbon $\mathrm{C}_{3}$ of conformer $\mathbf{A}$ (Scheme 2) is produced by reaction $\mathrm{R} 4$ (Scheme 1). This adsorbed radical is stabilized by resonance with a carbonyl group. The transfer of a second electron to the previous radical intermediate also occurs on the surface of $\mathrm{ZnS}^{*}$ facilitated by zinc sites to form an adsorbed carbanion depicted in reaction $\mathrm{R} 5$ (Scheme 1). The next steps are the sequential abstraction of protons from water (or hydronium for $\mathrm{pH}<7$ ) in reactions R6 and R7. Proton abstraction by reaction $\mathrm{R} 7$ occurs concomitantly to the surface desorption of succinic acid monoanion, as confirmed by the small rise in $\mathrm{pH}$ associated with the consumption of protons observed. Since the surface of $\mathrm{ZnS}$ is negatively charged at $\mathrm{pH}$ $>4.2,{ }^{3}$ the carboxylate group of the monoanions of fumaric and succinic acids are repelled from the surface, contributing to the desorption process of the product.

\section{CONCLUSIONS}

The data from experiments under periodic illumination demonstrate that the timespan needed to establish equilibrium condition between bulk and surface adsorbed fumaric acid monoanion is in the order of hundreds of microseconds. This conclusion is derived from modifying the period allowing replenishment of fumaric acid adsorption in the dark to contrast the depletion of reactive surface species during illumination. The simple zero-order kinetic behavior for the 
production of succinate indicates that the surface is quickly depleted of fumaric acid monoanion. The previous observation suggests that adsorption of fresh reagent limits (kinetic control) the zero-order rate of reaction. Therefore, the rate of electron transfer to the adsorbed species is limited by the rate of replenishment of fresh reactant from the solution. Further work should aim to advance this matter by studying the Langmuir isotherm derived from experiments at variable fumaric acid concentration that will change the surface coverage of $\mathrm{ZnS}$.

Characteristic surface carriers remain active for several hundred microseconds for electron transfer and a few millisecond for the loss of oxidizing holes. This study confirms that reactive intermediates in a photoexcited semiconductor exist for relative long times, as observed before for adsorbed $\mathrm{CO}_{2}$ undergoing reduction to $\mathrm{HCOO}^{-}$on the surface $\mathrm{ZnS}^{*}, 3$ when compared to the values measured by time-resolved spectroscopy of semiconductors (e.g., $150 \mathrm{fs} \leqslant \tau_{1 / 2}<100 \mu \mathrm{s}$ ). ${ }^{30}$ The photoproduction of succinic acid in aqueous colloidal suspensions of $\mathrm{ZnS}$ in the presence of $\mathrm{Na}_{2} \mathrm{~S}$ directly consumes monodissociated fumaric acid as the adsorbed species. The reported bandgap of $\mathrm{ZnS}$ in water based on the dependence of $R_{\mathrm{s}}$ on $\lambda_{\text {cut-off }}$ agrees well with previous findings for the production of formate. ${ }^{3}$ The measurement of $\Phi_{s}$ under periodic illumination provides important evidence that the time scale of redox processes on the surface of semiconductors-the effective transfer of reactive carriers-is in the same order for sorption-desorption equilibrium. For the previous reason the structure of the adsorbate affects the lifetime of the surfaceactive center of the photocatalyst. ${ }^{31}$ Overall, these results reveal new knowledge needed in the optimization of future applications of photocatalysis for fuel production, wastewater treatment, the abatement of air pollution, prebiotic chemistry, and abiotic photosynthesis. 6,30

\section{ASSOCIATED CONTENT}

\section{S Supporting Information}

The Supporting Information is available free of charge on the ACS Publications website at DOI: 10.1021/acs.jpcc.5b12380.

Context to the origin of life (PDF)

\section{AUTHOR INFORMATION}

\section{Corresponding Author}

*E-mail marcelo.guzman@uky.edu; phone (859) 323-2892 (M.I.G.).

\section{Notes}

The authors declare no competing financial interest.

\section{ACKNOWLEDGMENTS}

We thank research funding from NSF CAREER award (CHE1255290) to M.I.G. Partial support from the University of Kentucky by a Research Challenge Trust Fund Fellowship to R.Z. is gratefully acknowledged.

\section{ABBREVIATIONS}

$E^{0}$, standard reduction potential; $E_{\mathrm{BG}}$, bandgap; $\mathrm{h}^{+}$, oxidizing hole; $I_{0}$, effective photon flux; $k_{-\mathrm{H}_{2} S}$, first-order rate constant of sulfide decay; $R_{\mathrm{s}}$, rate of succinate production; $R_{\mathrm{HCOO}^{-}}$, rate of formate production; $\Phi_{\mathrm{s}}$, apparent quantum yield of succinate production; $\Phi_{\mathrm{HCOO}^{-}}$, apparent quantum yield of formate production; $\lambda_{\text {cut-off }}$ cut-off wavelength of irradiation; $\tau_{\mathrm{L}}$, bright interval time under periodic illumination; $\zeta$, zeta potential.

\section{REFERENCES}

(1) Habisreutinger, S. N.; Schmidt-Mende, L.; Stolarczyk, J. K. Photocatalytic reduction of $\mathrm{CO}_{2}$ on $\mathrm{TiO}_{2}$ and other semiconductors. Anoew. Chem., Int. Ed. 2013, 52, 7372-7408.

(2) Hisatomi, T.; Kubota, J.; Domen, K. Recent advances in semiconductors for photocatalytic and photoelectrochemical water splitting. Chem. Soc. Rev. 2014, 43, 7520-7535.

(3) Zhou, R.; Guzman, M. I. $\mathrm{CO}_{2}$ reduction under periodic illumination of ZnS. I. Phys. Chem. C 2014, 118, 11649-11656.

(4) Park, H.; Ou, H.-H.; Colussi, A. J.; Hoffmann, M. R. Artificial photosynthesis of $\mathrm{C} 1-\mathrm{C} 3$ hydrocarbons from water and $\mathrm{CO}_{2}$ on titanate nanotubes decorated with nanoparticle elemental copper and

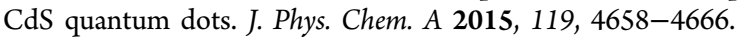

(5) White, J. L.; et al. Light-driven heterogeneous reduction of carbon dioxide: Photocatalysts and photoelectrodes. Chem. Rev. 2015, $115,12888-12935$.

(6) Guzman, M. I. Abiotic Photosynthesis: From Prebiotic Chemistry to Metabolism. In Origins of Life: The Primal Self-Organization; Egel, R., Lankenau, D.-H., Mulkidjanian, A. Y., Eds.; Springer: Berlin, 2011; pp 85-105.

(7) Guzman, M. I.; Martin, S. T. Oxaloacetate-to-malate conversion by mineral photoelectrochemistry: Implications for the viability of the reductive tricarboxylic acid cycle in prebiotic chemistry. Int. I. Astrobiol. 2008, 7, 271-278.

(8) Guzman, M. I.; Martin, S. T. Prebiotic metabolism: Production by mineral photoelectrochemistry of $\alpha$-ketocarboxylic acids in the reductive tricarboxylic acid cycle. Astrobiology 2009, 9, 833-842.

(9) Guzman, M. I.; Martin, S. T. Photo-production of lactate from glyoxylate: How minerals can facilitate energy storage in a prebiotic world. Chem. Commun. 2010, 46, 2265-2267.

(10) Zhang, X. V.; Martin, S. T. Driving parts of Krebs cycle in reverse through mineral photochemistry. I. Am. Chem. Soc. 2006, 128, 16032-16033.

(11) Zimmer, C. How and where did life on Earth arise? Science 2005, 309, 89-89.

(12) Mulkidjanian, A. Y. On the origin of life in the Zinc world: 1. Photosynthesizing, porous edifices built of hydrothermally precipitated zinc sulfide as cradles of life on Earth. Biol. Direct 2009, 4, 1-39.

(13) Mulkidjanian, A. Y.; Galperin, M. Y. On the origin of life in the Zinc world. 2. Validation of the hypothesis on the photosynthesizing zinc sulfide edifices as cradles of life on Earth. Biol. Direct 2009, 4, 137.

(14) Zhang, X. V.; Ellery, S. P.; Friend, C. M.; Holland, H. D.; Michel, F. M.; Schoonen, M. A. A.; Martin, S. T. Photodriven reduction and oxidation reactions on colloidal semiconductor particles: Implications for prebiotic syntheis. I. Photochem. Photobiol., A 2007, $185,301-311$.

(15) Hörner, G.; Johne, P.; Künneth, R.; Twardzik, G.; Roth, H.; Clark, T.; Kisch, H. Heterogeneous photocatalysis, part XIX. Semiconductor type A photocatalysis: role of substrate adsorption and the nature of photoreactive surface sites in zinc sulfide catalyzed C-C coupling reactions. Chem. - Eur. J. 1999, 5, 208-217.

(16) Nelson, D. L.; Cox, M. Lehninger Principles of Biochemistry, 4th ed.; W. H. Freeman: New York, 2004.

(17) Hatchard, C. G.; Parker, C. A. A new sensitive chemical actinometer. II. Potassium ferrioxalate as a standard chemical actinometer. Proc. R. Soc. London, Ser. A 1956, 235, 518-536.

(18) Williams, R.; Labib, M. E. Zinc sulfide surface chemistry: An electrokinetic study. I. Colloid Interface Sci. 1985, 106, 251-254.

(19) Becker, W. G.; Bard, A. J. Photoluminescence and photoinduced oxygen adsorption of colloidal zinc sulfide dispersions. $\underline{\text {. Phys. Chem }}$ 1983, 87, 4888-4893.

(20) CRC Handbook of Chemistry and Physics, 93rd ed.; CRC Press/ Taylor and Francis: Boca Raton, FL, 2013.

(21) Senger, B.; Voegel, J. C.; Schaaf, P. Irreversible adsorption of colloidal particles on solid substrates. Colloids Surf. A 2000, 165, 255285. 
(22) Aslam, M.; Mulla, I. S.; Vijayamohanan, K. Hydrophobic organization of monolayer-protected Au clusters on thiol-functionalized $\mathrm{Au}(111)$ surfaces. Langmuir 2001, 17, 7487-7493.

(23) Serpone, N. Relative photonic efficiencies and quantum yields in heterogeneous photocatalysis. I. Photochem. Photobiol. A 1997, 104, $1-12$.

(24) Mills, A.; Le Hunte, S. An overview of semiconductor photocatalysis. I. Photochem. Photobiol. A 1997, 108, 1-35.

(25) Cornu, C. J. G.; Colussi, A. J.; Hoffmann, M. R. Time scales and $\mathrm{pH}$ dependences of the redox processes determining the photocatalytic efficiency of $\mathrm{TiO}_{2}$ nanoparticles from periodic illumination experiments in the stochastic regime. I.Phvs. Chem. B 2003, 107, 3156-3160.

(26) Delgado, A. V.; Gonzalez-Caballero, F.; Hunter, R. J.; Koopal, L. K.; Lyklema, J. Measurement and interpretation of electrokinetic phenomena. I. Colloid Interface Sci. 2007, 309, 194-224.

(27) Kirby, B. Micro- and Nanoscale Fluid Mechanics: Transport in Microfluidic Devices; Cambridge University Press: 2010.

(28) Zhao, J.; Holmes, M. A.; Osterloh, F. E. Quantum confinement controls photocatalysis: A free energy analysis for photocatalytic proton reduction at CdSe nanocrystals. ACS Nano 2013, 7, 43164325.

(29) Ahmed, R.; Zhao, L.; Mozer, A. J.; Will, G.; Bell, J.; Wang, H. Enhanced electron lifetime of CdSe/CdS quantum dot (QD) sensitized solar cells using $\mathrm{ZnSe}$ core-shell structure with efficient regeneration of quantum dots. I. Phvs. Chem. C 2015, 119, 2297-2307.

(30) Mohamed, H. H.; Bahnemann, D. W. The role of electron transfer in photocatalysis: Fact and fictions. Appl. Catal., B 2012, 128, 91-104.

(31) Emeline, A. V.; Ryabchuk, V. K.; Serpone, N. Dogmas and Misconceptions in Heterogeneous Photocatalysis. Some Enlightened Reflections. I. Phvs. Chem. B 2005, 109, 18515-18521.

(32) Kisch, H. Semiconductor Photocatalysis: Principles and Applications: John Wiley \& Sons: Weinheim, Germany, 2014.

(33) Wang, M.; Zhang, Q.; Hao, W.; Sun, Z. Surface stoichiometry of zinc sulfide and its effect on the adsorption behaviors of xanthate. Chem. Cent. I. 2011, 5, 73.

(34) Sun, Z.; Forsling, W.; Rönngren, L.; Sjöberg, S. Surface reactions in aqueous metal sulfide systems. 1. Fundamental surface reactions of hydrous $\mathrm{PbS}$ and $\mathrm{ZnS}$. Int. I. Miner. Process. 1991, 33, 83-93.

(35) Rönngren, L.; Sjöberg, S.; Sun, Z.; Forsling, W.; Schindler, P. Surface reactions in aqueous metal sulfide systems: 2 . Ion exchange and acid/base reactions at the $\mathrm{ZnSH}_{2} \mathrm{O}$ interface. L. Colloid Interface Sci. 1991, 145, 396.

(36) Pearson, R. G. j. Hard and soft acids and bases, HSAB, part 1 : Fundamental principles. I. Chem. Educ. 1968, 45, 581.

(37) Brown, C. J. The crystal structure of fumaric acid. Acta Crvstallogr. 1966, 21, 1-5.

(38) Bednowitz, A. L.; Post, B. Direct determination of the crystal structure of $\beta$-fumaric acid. Acta Crystallogr. 1966, 21, 566-571.

(39) Miehlich, B.; Savin, A.; Stoll, H.; Preuss, H. Results obtained with the correlation energy density functionals of Becke and Lee, Yang and Parr. Chem. Phvs. Lett. 1989, 157, 200-206.

(40) Lee, C.; Yang, W.; Parr, R. G. Development of the Colle-Salvetti correlation-energy formula into a functional of the electron density. Phys. Rev. B: Condens. Matter Mater. Phys. 1988, 37, 785.

(41) McLean, A. D.; Chandler, G. S. Contracted Gaussian basis sets for molecular calculations. I. Second row atoms, $Z=11-18$. I. Chem. Phys. 1980, 72, 5639-5648.

(42) Krishnan, R. B. J. S.; Binkley, J. S.; Seeger, R.; Pople, J. A. Selfconsistent molecular orbital methods. XX. A basis set for correlated wave functions. I. Chem. Phvs. 1980, 72, 650-654. 